\title{
Letters
}

\section{Sentinel lymph node biopsy}

\section{Not yet standard of care for melanoma}

EDITOR-Kell and Kerin wrote about sentinel lymph node biopsy in breast cancer and melanoma. ${ }^{1}$ This is a staging procedure with a well established role in breast cancer, reducing the need for dissection of the axillary node. The indications and advantages for sentinel lymph node biopsy in melanoma are not confirmed, and it is certainly not the established treatment implied in the editorial.

Sentinel node status in melanoma is indeed the best staging and prognostic indicator: patients with negative results have a better prognosis then those with positive results. However, there is no evidence from randomised clinical trials that completion lymphadenectomy (sometimes known as selective lymphadenectomy) in patients with positive sentinel node biopsies offers any survival advantage. Neither is there any adjuvant therapy that can influence the natural history and benefit patients who are sentinel node positive. ${ }^{3}$ Concern has recently been raised about the possible increased incidence of local and in-transit recurrence in patients with positive sentinel nodes who undergo completion lymphadenectomy. ${ }^{4}$ This iatrogenic complication carries an ominous prognosis and is probably explained by lymphatic obstruction and entrapment of melanoma cells in transit to the regional nodes.

The final decision for or against sentinel lymph node biopsy in melanoma must await the result of a multicentre selective lymphadenectomy trial, which will not be published before 2006. ${ }^{5}$ Until then, patients deserve to be informed that sentinel lymph node biopsy in melanoma is an investigational procedure with an unknown outcome; the significance of a possibly increased incidence of local or in-transit recurrence should be included when obtaining informed consent.

A degree of editorial balance in the literature should be encouraged, rather than the present unbridled enthusiasm for an attractive but unproved concept.

J Meirion Thomas consultant surgical oncologist sarcoma@mac.com

Matthew A Clark consultant surgical oncologist Royal Marsden Hospital Melanoma and Sarcoma Unit, London SW3 6JJ

Competing interests: None declared.

1 Kell MR, Kerin MJ. Sentinel lymph node biopsy. BMJ 2004;328:1330-1. (5 June.)
2 Roberts DL, Anstey AV, Barlow RJ, Cox NH, Newton Bishop J, Corrie PG, et al. UK guidelines for the management of

3 Wheatley K, Ives N, Hancock B, Gore M, Eggermont A Suciu S. Does adjuvant interferon-alpha for high Suciu S. Does adjuvant interferon-alpha for hig Sisk melanona provide a worthwhile benefit? A 2003.29:241-59.

Thomas JM, Clat MA Does completion lymphadenecThomas JM, Clark MA. Does completion lymphadenectomy in sentinel node positive patients increase the risk of local and in-transit recurrence in melanoma? Eur J Surg Oncol 2004 (in press). doi 10.1016/j.ejso.2004.04.004. Morton DL, Thompson JF, Essner R, Elashoff R, Stern SL Nieweg OE, et al. Validation of the accuracy of intraoperative lymphatic mapping and sentinel lymphadenectom for early-stage melanoma: a multicenter trial. Multicente Selective Lymphadenectomy Trial Group. Ann Surg
1999:230:453-63.

\section{Optimum method remains to be} determined

EDITOR-Kell and Kerin report on the current status of sentinel lymph node biopsy in the surgical treatment of breast cancer and melanoma. ${ }^{1}$ They say that the detection of occult malignancy in lymph nodes in breast cancer signifies a worse prognosis and that the rapid intraoperative detection of malignant cells by immunocytochemistry will vitalise sentinel node biopsy-both assertions may be premature. Although a number of earlier studies have shown a worse prognosis, a more recent study using multivariate analysis has indicated that occult metastases are of no independent prognostic importance. $^{2}$

The optimum method by which lymph nodes removed in the course of breast cancer surgery should be examined, including the utility of immunocytochemistry, remains to be determined. Touch imprint cytology is a reliable method for the detection of carcinoma cells, but may not reliably discriminate between macrometastases (deposits $>2 \mathrm{~mm}$ ), micrometastases (deposits $<2 \mathrm{~mm}$ ), and small numbers of individual tumour cells affecting the peripheral sinus of a lymph node. ${ }^{3}$ Further studies, preferably with large numbers of patients and adequate follow up, will be required before these techniques enter routine practice.

Ervine D Long consultant histopathologist ervine.long@hey.nhs.uk

John R Read consultant histopathologist Hull Royal Infirmary, Hull HU3 2JZ

Competing interests: None declared.

1 Kell MR, Kerin MJ. Sentinel lymph node biopsy. BMJ 2004;328:1330-1. (5 June.)

2 Millis RR, Springall R, Lee AHS, Ryder K, Rytina ERC, Fentiman IS. Occult axillary lymph node metastases are of no prognostic significance in breast cancer. $\mathrm{Br} J$ Cancer 2002;86:396-401
3 Salem AA, Douglas-Jones AG, Sweetland HM, Newcombe RG, Mansel RE. Evaluation of axillary lymph nodes usin touch imprint cytology and immunohistochemistry. $\mathrm{Br} J$ Surg 2002;89:1386-9.

\section{Sentinel node technique has drawbacks}

EDITOR-Among the possible drawbacks of sentinel node biopsy, discussed by Kell and Kerin, ${ }^{1}$ is the risk of false positive findings because of reactive lymph node swelling in the biopsy site. Periodic follow up of the sampled lymph node area has become a common practice after sentinel node biopsy, mostly based on palpation and ultrasonography. Swelling of axillary or inguinal lymph nodes reactive to sentinel node biopsy is likely to occur; a reaction in these sites is a common event, even after lesser injuries.

Unfortunately, both palpation and ultrasonography are poorly accurate in assessing enlarged nodes, and false positive reports are likely to occur: fine needle aspiration may help, if positive, but considering that in these cases a greater diagnostic aggressiveness is expected, a false positive assessment might end in further surgical biopsy of the lymph node. A more aggressive surveillance regimen is expected in patients undergoing sentinel node biopsy, as is a higher frequency of false positive reports and unnecessary invasive procedures.

This possible negative effect is rarely addressed in the literature, although it might substantially reduce the benefits of sentinel node biopsy, a technique aimed uniquely at improving quality of life. Studies aiming to show the cost effectiveness of sentinel node biopsy should mainly address quality of life as the end point, and the frequency of invasive procedures to assess false positive findings at periodic follow up should be a variable carefully taken into account.

Stefano Ciatto head

Department Diagnostic Imaging, Centro per lo Studio e la Prevenzione Oncologica, Viale Volta 171, I-50131, Florence, Italy

s.ciatto@cspo.it

Competing interests: None declared.

1 Kell MR, Kerin MJ. Sentinel lymph node biopsy. BMJ 2004;328:1330-1. (5 June.)

\section{Authors' reply}

EDITOR-As we said, numerous issues about sentinel lymph node biopsy will be answered only by prospective clinical trials. The technique is a very important minimally invasive predictive prognostic indicator in breast cancer and melanoma. In these conditions performing either no lymphatic surgery or lymphatic clearance surgery on all patients would be neither evidence based nor safe. 
We agree with Thomas and Clark that there is a degree of nihilistic predetermination in melanoma owing to the lack of an appropriate therapeutic intervention, but the concept of sentinel lymph node biopsy leading to in transit and more aggressive local disease is counterintuitive and not supported by current literature.

We agree with Long and Read in principle, though we have quoted the current seminal article on sentinel lymph node biopsy micrometastases, which examines almost 1000 patients compared with a more recent paper with fewer than half this number. ${ }^{12}$ The definitive answer will hopefully be answered by ACOSOG Z10, which will examine the clinical outcome of breast cancer patients with sentinel lymph node biopsy micrometastases. ${ }^{3}$

In our experience of performing several hundred sentinel lymph node biopsies for both melanoma and breast cancer we have not found false positive lymphadenopathy after the biopsy to be a real clinical concern. We believe that there is no evidence in the literature to support this either.

Patients should be given the most accurate prognostic information available. The evidence base for widespread utilisation of the best prognostic test (sentinel lymph node biopsy) has led to the use of this technique in north America and many other countries; enthusiasm is beginning to grow in the United Kingdom.

Malcolm R Kell senior specialist registrar malcolmkell@eircom.net

Michael J Kerin consultant surgeon

Department of Surgery, National Breast Cancer Screening Programme, Eccles Unit, Mater Misericordiae Hospital, Dublin 7, Republic of Ireland Competing interests: None declared.

1 International (Ludwig) Breast Cancer Study Group. Prognostic importance of occult axillary lymph node micromenostic importance of occult axillary lymph node micro 2 Millis RR, Springall R, Lee AHS, Ryder K, Rytina ERC, Fentiman IS. Occult axillary lymph node metastases are of no prognostic significance in breast cancer. Br J Cancer 2002;86:396-401.

American College of Surgeons Oncology Group. A prognostic trial of sentinel node and bone marrow micrometastases in women with clinical T1 or T2 NO MO breast cancer. (accessed 24 Jun 2004)

\section{Review of instruments for peer assessment of physicians}

\section{Clinics with peers keep you on the} straight and narrow...

EDITOR-Evans et al raise several points in their article reviewing methods of peer assessment.

Firstly, joint clinics are excellent for observing colleagues-and being observed by them-in genuine clinical situations. I regularly hold joint clinics with colleagues from overlapping specialties, such as genetics, neurology, ophthalmology, etc. I learn new ways of communicating with patients and families: opening the consultation, giving explanations and (bad) news. Opportunities exist to question colleagues at the time of the consultation-for example, why are you doing or not doing an investigation?
It is non-threatening, constructive, and leads to reflective discussion.

Secondly, 360 degree appraisals are popular but have not been validated. ${ }^{2}$ Any doctor worth their salt will challenge the status quo. We should ask difficult questions of ourselves (especially), colleagues, other health professionals, administrators, and sometimes patients and parents. Fear of getting poor reports will mean that either the appraisal forms are given to those who like us or we will be subdued in challenging poor, lazy, or inefficient practice.

Thirdly, doctors' "poor communication" was raised. ${ }^{3}$ No group in the health service sees the number of patients, works the hours, and makes the number of decisions of consequence that doctors do. Doctors give difficult, unpleasant, complicated information to people who often feel upset, anxious, angry, and guilty. What is remarkable is how often doctors communicate well under those circumstances rather than badly. The doctor-patient relationship is two way. It is specious to assume that poor communication would be reduced or eliminated if the doctor had better communication skills.

Charles Essex consultant neurodevelopmental paediatrician

Child Development Unit, Gulson Hospital,

Coventry CV1 2HR

Room101@ntworld.com

Competing interests: None declared.

1 Evans R, Elwyn G, Edwards A. Review of instruments for peer assessment of physicians. BMJ 2004;328:1240-3. (22 May.)

2 Ben-David MF, Snadden D, Hesketh A. Linking appraisal of PRHO professional competence of junior doctors to their education. Med Teach 2004;26:63-70.

3 Clark GB, Allen J, Cooper D, Head JO. Personality Clark GB, Allen J, Cooper D, Head JO. Personality ine for the teach of 2004:38:177-86.

\section{$\ldots$ and our impact on one another is important}

EDITOR-Evans et al reviewed instruments for peer assessment of physicians. ${ }^{1}$ Decades of experience helping healthcare professionals learn how to seek, give, receive, and process feedback has led to several conclusions. ${ }^{2}$ Rigorous psychometric techniques have little place when what is being explored is the impact human beings have on one another when they interact face to face.

The primary form of validity that really matters is face validity, specifically because the judgments are subjective- the "subjects" are human beings. This same fact explains the "poor agreement between observers of the same event" when "humanistic qualities" are of concern. The "observer," after all, is not the person experiencing the event. Furthermore, even when a person exhibits the same behaviour towards two separate people, he or she can, and, as our own research documents, often does, experience the behaviour differently. As well they should, for they, too, are different human beings.

Perhaps in trying to be "scientifically rigorous" the essential nature of human interactions is being missed. We are not, however, arguing against the use of instruments. Rather, we are emphasising that the most useful instrument will be one that enables two people to get a clear, nonjudgmental, behaviourally specific (versus dealing with crucial but immeasurable and judgmental qualities such as "honesty" and "trust") picture of the impact they are having on one another. We highlight the word they because our experience has been, and increasing numbers of others are reporting, that the current fad of anonymous aggregated 360 degree assessments is, indeed, iatrogenic. Faceless mechanisms that purport to improve the quality of face-to-face human encounters are an oxymoron.

Irwin M Rubin president

Temenos, 37 Kawananakoa Place, Honolulu, HI 96917, USA

temenos@lava.net

Sarah W Fraser visiting professor, Middlesex University 5 Cuddington Road, Dinton, Aylesbury,

Buckinghamshire HP18 0AB

Competing interests: None declared.

1 Evans R, Elwyn G, Edwards A. Review of instruments for peer assessment of physicians. BMJ 2004;328:1240-3. (22 May)

2 Rubin IM, Campbell TJ. The ABCs of effective feedback; a guide for caring professionals. San Francisco: Jossey Bass, 1998.

\section{Ginkgo biloba and acetazolamide for acute mountain sickness}

\section{Exclusion of high risk, low status groups perpetuates discrimination and inequalities}

EDITOR-Gertsch et al report the results of a randomised controlled trial of ginkgo biloba and acetazolamide for acute mountain sickness in trekkers in the Everest region of Nepal. ${ }^{1}$ However, it is not clear why entry to the study was restricted to non-Nepali trekkers. Many Nepalis working in the trekking industry in the Everest region are not stereotypical. Sherpas who have lived their whole life at altitude and are at similar, if not greater, risk of acute mountain sickness as Western trekkers (see www.portersprogress.org). Although including Nepalis at risk of acute mountain sickness in the study would have entailed some additional logistical arrangements, these should not be beyond the abilities of a large, international research team.

Studies such as this, which exclude high risk, low status groups for no obvious reason, perpetuate discrimination and inequalities. Evidence is required on how to prevent acute mountain sickness in all groups, and not just rich Western tourists.

Jean Adams research fellow

School of Population and Health Sciences, University of Newcastle upon Tyne, Newcastle upon Tyne NE2 4HH

j.m.adams@ncl.ac.uk

Competing interests: None declared.

1 Gertsch JH, Basnyat B, Johnson EW, Onopa J, Holck PS Randomised, double blind, placebo controlled comparison of ginkgo biloba and acetazolamide for prevention of son of ginkgo biloba and acetazolamide for prevention of acute mountain sickness anong Himalayan PHAIT) BNJ prevention of high altitude illness trial (PHAIT) BMJ 2004;328:797-801. (3 April.) 
Bias in participants may underestimate effectiveness of agents

EDITOR-In their randomised controlled trial of gingko biloba and acetazolamide for preventing acute mountain sickness Gertsch et al do not include data on eligible trekkers who declined enrolment. ${ }^{1}$ These data are important as the trial participants may not be representative of all non-Nepali trekkers. A bias in participants may underestimate the effectiveness of either agent. This is particularly important for gingko, which is stated to be no more effective than placebo.

Many trekkers arriving in Nepal will have established views on drug treatments for altitude sickness. Some will already be in possession of their drug of choice. Such people are likely to refuse randomisation to drug or placebo and will therefore have been excluded from the trial. If a significant number of these had perceived prior benefit from gingko, its effectiveness will have been underestimated.

From the information provided it is impossible to comment on the noneffectiveness of gingko in preventing acute mountain sickness.

Heather L Elphick specialist registrar, geriatric medicine

Northern General Hospital, Sheffield S5 7AU elphickdh@hotmail.com

David A Elphick specialist registrar, gastroenterology Royal Hallamshire Hospital, Sheffield S10 2JF

Competing interests: None declared.

1 Gertsch JH, Basnyat B, Johnson EW, Onopa J, Holck PS Randomised, double blind, placebo controlled comparison of ginkgo biloba and acetazolamide for prevention of acute mountain sickness among Himalayan trekkers: the prevention of high altitude illness trial (PHAIT) BMJ 2004;328:797-801. (3 April.)

\section{Authors' reply}

EDITOR-The recruitment of Western trekkers in the prevention of high altitude illness trial (PHAIT) study was based on logistics and practicality. Sherpas and other Nepalis residing in or adjacent to the Everest region and above $2000 \mathrm{~m}$ are highly resistant to the effects of altitude and would thus be poor research participants. Although many Nepalis working in the Everest region reside at altitudes below $1500 \mathrm{~m}$ (potentially eligible research candidates), a fair proportion live in higher regions that would make some degree of acclimatisation likely.

Furthermore, many lowland dwelling Nepalis working as porters will relocate temporarily for the season to wait for work at the airstrip in Lukla $(2500 \mathrm{~m})$, where tourists begin their trek. Many will therefore acclimatise en masse in the first weeks of the season, providing a narrow window for enrolment. One of us (BB) tried in 2001 to study lowland porters as subjects but failed to collect adequate data primarily because of poor enrolment and a high rate of loss to follow up. We agree that more evidence is needed about the epidemiology and treatment of altitude sickness in lowland Nepalis.

Excluding bias in clinical trials conducted in the Everest region is inherently problematic because of logistical issues unique to the area. Healthy vacationing trekkers who decline participation in a clinical trial are often not interested in taking the time to provide further information. The argument against bias in our model stems from the large homogeneous cohort evaluated under strict double blinding and in agreement with CONSORT guidelines, as well as the lack of any differences within groups or in comparing those enrolled with those lost to follow up. ${ }^{1}$ The failure to collect data on those who chose not to enrol in the trial is a weakness of the PHAIT study and was dealt with in a subsequent 旁 clinical trial (B Basnyat and J Gertsch, unpublished data; see full reply on bmj.com).

Given these data, we are confident that the PHAIT study is a fair and convincing test of ginkgo's efficacy under the conditions tested.

Jeffrey $\mathbf{H}$ Gertsch resident physician

Department of Internal Medicine, Maricopa Medical Center, 2601 E Roosevelt Avenue number O-D-10, Phoenix, AZ 85008, USA

jeffgertsch@hotmail.com

Buddha Basnyat medical director

Himalayan Rescue Association, Nepal International Clinic, GPO Box 3596, Laldurbarmag 47,

Kathmandu, Nepal

nic@naxal.wlink.com.np

E William Johnson resident physician

Department of Surgery, University of Washington, Seattle, WA 98195-6410, USA

billjohn@hawaii.edu

Peter S Holck associate professor

Department of Public Health Sciences and

Epidemiology, University of Hawaii, Honolulu, HI Epide

holck@hawaii.edu

Competing interests: JHG has been funded by Pharmaton to attend a research symposium and received reimbursement for on-site living costs incurred during the implementation period of the study. 1 Begg C, Cho M, Eastwood S, Horton R, Moher D, Olkin I,
et al. Improving the quality of reporting of randomized
controlled trials: the CONSORT statement. JAMA
1996;276:637-9.

Full reply is available on bmj.com $\mathrm{P}+$

\section{National screening programme for chlamydia exists in England}

EDITOR-The news article on the coverage of chlamydia screening in England was disappointing. ${ }^{1}$ Contrary to its suggestion that no "formal" chlamydia screening programme in England exists, the national chlamydia screening programme in England was established in 2002 after a successful pilot study in Portsmouth and Wirral and publication of the government's national sexual health and HIV strategy implementation plan. ${ }^{2}$ It is currently the only such screening programme in Europe (N Low, British Association for Sexual Health-American Sexually Transmitted Diseases Association spring meeting, Bath, May 2004).

Over the past 18 months 26 local chlamydia screening programmes have been implemented in two phases across England, covering over $25 \%$ of all primary care trusts. A third phase of implementation will be launched in the autumn of 2004. The programme offers opportunistic screening to women and men younger than 25 in a range of settings outside genitourinary medicine. National guidelines for screening have been produced. ${ }^{3}$ The programme is guided by a multidisciplinary steering committee and operates within the framework of the national screening committee. The first year's annual report will be published in autumn 2004 .

By suggesting that screening is the only effective intervention, the news article also obscures the range of prevention activities that are taking place concurrently. These include implementation of the highly sensitive nucleic acid amplification tests; public education campaigns; the development of rapid, near patient, diagnostic tests for chlamydia; and allied research and evaluation. No government indecision has occurred in this matter

The so called slow progress of implementation reflects the time taken to roll out this complex public health programme, in a considered manner, over five yearsprecisely to avoid unmanaged growth. The scale of the exercise is considerable, given the unique nature of this programme, the range of sites being included, and the immense challenges of implementation in the context of a changing NHS.

K A Fenton consultant epidemiologist kevin.fenton@hpa.org.uk

D Scott LaMontagne epidemiologist HIV and STI Department, Health Protection Agency Communicable Disease Surveillance Centre, London NW9 5EQ

Sarah Randall consultant, reproductive health Ella Gordon Unit, St Mary's Hospital, Portsmouth PO3 6AF

KAF is chair of the National Chlamydia Screening Steering Group, and SR is an adviser to the Department of Health.

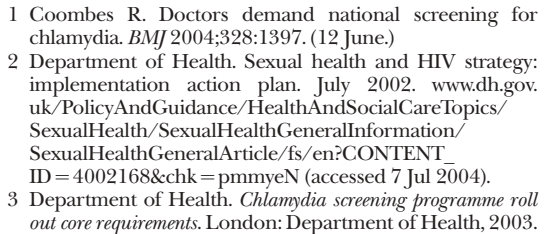

1 Coombes R. Doctors demand national screening for chlamydia. BMJ 2004;328:1397. (12 June.)

2 Department of Health. Sexual health and HIV strateg: Departion strategy: mplentation action plan. July 2002. Www.dh.gov: uk/PolicyAndGuidance/HealthAndSocialcareTopics SexualHealth/SexualHealthGenerallnformation ID $=40021$ GeneralArticle/s/en?CONTENT $\mathrm{D}=4002168$ chk $=$ pmmyeN $($ accessed $7 \mathrm{Jul} 2004)$. 3 Department of Health. Chlamydia screening programme roll
out core requirements. London: Department of Health, 2003.

\section{Discharge rates for suspected acute coronary syndromes}

\section{Is morbidity or empowerment increasing?}

EDITOR-In their population based analysis Murphy et al reported a marked increase in morbidity rates for suspected acute coronary syndromes between 1990 and 2000. ${ }^{1}$ How- 


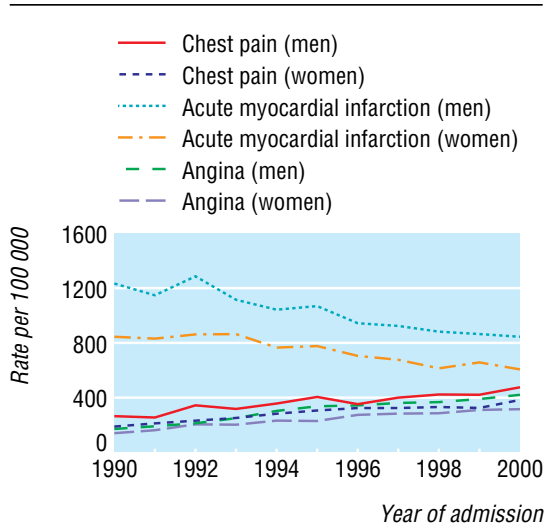

Population discharge rates for acute coronary syndromes in people over 75 in Scotland ${ }^{1}$

ever, we need to eliminate all reasonable doubt that the trend represents an actual rise and is not simply the result of empowerment of the population, enabled to recognise symptoms and enforce their rights better.

For example, among "new fashioned" elderly people, this factor may contribute to the reported rise in morbidity which, in the case in point, may not be due solely to the ageing population process. The morbidity rate trends in Scotland by urban and rural areas would be helpful. Traditionally, rates of use are lower in rural areas for partly cultural reasons. ${ }^{23}$

Aldo Mariotto director

Primary Health Care Unit Health Authority N 17, V G Marconi 19, 35043 Monselice (PD), Italy pghid@libero.it

Competing interests: None declared.

1 Murphy NF, MacIntyre K, Capewell S, Stewart S, Pell J, Chalmers J, et al. Hospital discharge rates for suspected acute coronary syndromes between 1990 and 2000: population based analysis. BMJ 2004;328:1413-4. (12 June.)

2 Sheikh K, Bullock C. Urban-rural differences in the quality of care for Medicare patients with acute myocardial infarcof care for Medicare patients with acute
tion. Arch Intern Med 2001;161:737-43.

3 Mariotto A. Urban-rural differences in the quality of care for Medicare patients with acute myocardial infarction.

\section{Clinical assessment tools need improving}

EDITOR-Murphy et al show some interesting trends in hospital discharge rates from 1990 to 2000 by age: a decline in discharge rates for acute myocardial infarction and rising trends for chest pain and angina. ${ }^{1}$ I agree with their conclusion, that these trends press the need for expansion of coronary services.

The rise in chest pain rates needs careful evaluation as this might represent a trend in queue jumping in overcrowded hospitals. A recent study in two urban cardiac referral centres in Canada has reported a 5\% false negative rate for emergency room clinical assessment regarding acute coronary syndrome. ${ }^{2}$ Therefore, in view of the seriousness of this symptom and high associated costs of thorough cardiac evaluation, a need exists for improvement in the clinical assessment tools.

Waseem Sharieff $P h D$ candidate Hospital for Sick Children, University of Toronto, 555 University Avenue \# 8259, Canada M5G 1X8 doc.sharieff@utoronto.ca

Competing interests: None declared.
1 Murphy NF, MacIntyre K, Capewell S, Stewart S, Pell J, Chalmers J, et al. Hospital discharge rates for suspected acute coronary syndromes between 1990 and 2000: population based analysis. BMJ 2004;328:1413-4. (12 June.)

Christenson J, Innes G, McKnight D, Boychuk B, Grafstein E, Thompson C, et al. Safety and efficiency of emergency department assessment of chest discomfort. CMAJ 2004:170:1803-7.

\section{Authors' reply}

EDITOR-Mariotto assumes that "new fashioned" elderly people might be more able to recognise their symptoms and demand their rights. Although the greatest percentage change in population rates in each diagnostic subgroup was in elderly people, the major increase in absolute numbers of admissions occurred in those under the age of 75. From 1990 to 2000 the median age of patients admitted to hospital with a possible acute coronary syndrome decreased (from 61 to 59 years in men and from 68 to 65 years in women), as did the median age of patients admitted with chest pain (from 52 to 51 years in men and from 56 to 55 years in women).

Sharieff thinks that the rise in emergency admissions might reflect "queue jumping" (presumably for coronary revascularisation). This seems unlikely over a period when the waiting time for revascularisation fell markedly in Scotland.

Niamh Murphy research fellow

John McMurray professor

j.momurray@bio.gla.ac.uk

Department of Cardiology, Western Infirmary, Glasgow G12 8QQ

Kate MacIntyre specialist registrar

Department of Public Health, University of

Glasgow, Glasgow G12 8RZ

Competing interests: None declared.

\section{Tracking system for studies should be in place}

EDIToR-GlaxoSmithKline's recent legal troubles resulting from not publishing negative results of clinical trials on the antidepressant paroxetine are just part of a larger problem of publication bias in modern research. ${ }^{1}$

There has been evidence that the literature that is published is more likely to be positive than chance alone might predict. ${ }^{2}$ There have even been links shown between positive trials and industry sponsorship. ${ }^{3}$ But these cases, although they are alarming, should not blind us to the general problem of negative results not being reported Proper analysis of new medical treatments requires properly weighing the evidence for the new treatment.

The proper solution to the underreporting of negative results is to track all clinical trials so that we can ensure that the results of such trials are properly reported. It is important for both journals and investigators to work together to ensure that this occurs. Had such a system been in place, it would have been much more difficult for GlaxoSmithKline to conceal these results.

J A C Delaney statistician, clinical epidemiology Royal Victoria Hospital, R 4.36, 687 Pine Avenue W, Montreal, OC, Canada H3A 1A1 chris.delaney@clinepi.mcgill.ca
Competing interests: None declared.

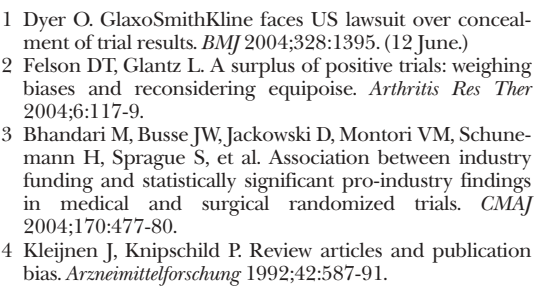

Kleijnen J, Knipschild P. Review articles and publication bias. Arzneimittelforschung 1992;42:587-91.

\section{Prisons show prophylaxis for close contacts may indeed help in next flu pandemic}

EDITOR-Balicer et al's editorial on tackling the next influenza pandemic highlights the potential of chemoprophylaxis of close contacts in managing community based influenza pandemics. ${ }^{1}$ One setting in which such a strategy shows promise is prisons.

The influenza epidemic in San Quentin prison in April and May 1918, which presumably struck $26 \%$ of the 1900 prisoners, is thought to be one of the primary foci of the 1918-20 pandemic. ${ }^{2}$ Documented outbreaks of flu in prisons have been rare since then. ${ }^{3}$ However, our modelling studies and the limited experience with managing such a prison outbreak indicate that quarantining clinically ill inmates in their cells or a health facility and giving antiviral prophylaxis to inmates and frontline staff in the same "wing" of the prison in which the outbreak occurred provide a more favourable cost benefit than annual mass vaccination, or a "do nothing" approach. ${ }^{3}$

In estimating such cost benefits, we took into consideration the rarity of influenza outbreaks in prisons (which means "wasteful" vaccination in the non-epidemic years), the high costs of maintaining prisoners' security in off site settings, the relative "worthlessness" of prisoners vis à vis economic valuations of epidemics, ${ }^{4}$ and the probably very low mortality among inmates because of average younger age.

While the World Health Organization has developed formal strategies for managing diseases such as tuberculosis in prisons, currently no formal WHO endorsed guidelines exist for influenza. This issue requires urgent attention.

Niyi Awofeso conjoint associate professor of public health

University of New South Wales, Sydney, Australia, Population Health Unit, NSW Corrections Health Service, PO Box 150, NSW 2036, Australia niyiawofeso@hotmail.com

Competing interests: None declared.

1 Balicer RD, Huerta M, Grotto I. Tackling the next influenza pandemic. BMJ 2004;328:1391-2. (12 June.)

Kolata G. Flu: the story of the great influenza pandemic of 1918 and the search for the virus that caused it. New York: Farar, Strauss, Giroux, 1999:10.

3 Awofeso N, Fennell M, Walizzaman Z O'Connor C, Pittam

$\mathrm{D}$, Boonwaat L, et al. Influenza outbreak in a correctional D, Boonwaat L, et al. Influenza outbreak in a cor,

facility. Aust N ZJ Public Healln 2001,25:413-6. Nichol KL, Mallon KP, Mendelman PM. Cost-benefit of influenza vaccination in healhy, working adults: an ated influenza virus vaccine. Vaccine 2003;16:2216-26. 